\title{
Os Cursos de Engenharia e seus Setores Regulador, Fiscalizador e de Livre Iniciativa de Mercado
}

\section{Engineering courses and their Regulation, Fiscalization and Free Initiative Market Sections}

Artigo
Original

Sergio Luiz Taranto de Reis 1

Original

Paper

\begin{abstract}
Palavras-chaves: Resumo
Curso Os cursos de engenharia no Brasil vem se constituindo em tema de estudo freqüente devido à nova postura do mercado de trabalho no país e ao

Engenharia

Mercado de

Trabalho

Instituições de Ensino Superior Programa de Aceleração da Economia - PAC. A evolução da economia de mercado tem modificado o perfil educacional e profissional da engenharia no Brasil, envolvendo setor regulador da educação, fiscalizador da profissão e de livre iniciativa de mercado a se questionarem e buscar juntos um caminho homogêneo e conciliador para o futuro profissional de engenharia. O Ministério da Educação - MEC que regulamenta o setor de educação e fiscaliza as Instituições de Ensino Superior, controlando as autorizações e reconhecimentos de cursos, o Conselho Federal de Engenharia - CONFEA que fiscaliza a atuação dos profissionais de engenharia e as exigências do mercado profissional, formam o tripé que sustenta e dá a estabilidade à formação do engenheiro.
\end{abstract}

\begin{abstract}
The courses of engineering in Brazil come if constituting in subject offrequent study which had the new position of the market of work in the country and to the "Program of Acceleration of Economy-PAC". The evolution of the market economy has modified the educational and professional profile of engineering in Brazil, having involved sectors regulating of the education, fiscalization of the profession and free initiative of market if to question and to search a homogeneous and whitewashing way for the professional future of engineering together. The Ministry of the Education - MEC that regulates the education sector and fiscalizes the Institutions of Superior Education controlling the authorizations and registers of courses, the Federal Advice of Engineering - CONFEA that fiscalizes the performance of the engineering professionals and the requirements of the professional market, form the tripod that supports and of a stability to the formation of the engineer.
\end{abstract}

Key words:

Course

Engineering

Market of Work

Institutions of Superior Education

\section{Introdução}

A engenharia no Brasil deu seus primeiros passos, de forma sistemática, ainda no período colonial, com a construção de fortificações e igrejas. Logo em 1549, com a decretação do Governo Geral, o engenheiro civil Luiz Dias foi incumbido pelo "governador das terras do Brasil", Tomé de Souza, de levantar os muros da cidade de Salvador (BA), a capital. Dias acabou construindo também o edifício da alfândega e o sobrado de pedrae-cal da Casa da Câmara e Cadeia, que se tornou célebre como o primeiro do gênero na colônia. Mas a criação de uma escola de Engenharia Civil brasileira só se daria 258 anos depois, com a chegada da Família Real ao País, em 1808, e a conseqüente fundação 
da Real Academia Militar do Rio de Janeiro. Seu objetivo era formar oficiais da artilharia, além de engenheiros e cartógrafos. Em 1842, a academia foi transformada em Escola Central de Engenharia e, 32 anos depois, convertida em curso exclusivo de Engenharia Civil. Essa instituição é, hoje, a Escola Nacional de Engenharia.

O desafio que se apresenta no ensino da engenharia no Brasil, espelha-se num cenário nacional de crescimento com o Programa de Aceleração do Crescimento PAC, em que se encontra carente de 50 mil novos engenheiros para a realização de suas obras e um cenário mundial que demanda uso intensivo da ciência e tecnologia e está a exigir profissionais altamente qualificados e comprometidos com as condições sociais e econômicas da sociedade e com o meio ambiente, fundamentado na lógica dos valores, da crítica e do alcance da ética.

O novo cenário profissional deve contemplar aqueles que possam exibir em seu perfil além dos aspectos tais como: iniciativa, criatividade, capacidade de liderança, responsabilidade social, empreendedorismo e empregabilidade e forte embasamento conceitual. Além dos conhecimentos técnicos e específicos o novo profissional deve saber observar o mercado e ter os conhecimentos adequados sobre relações humanas, impactos tecnológicos sobre o meio ambiente, finanças e direito trabalhista e do consumidor.

Como conseqüências, o conceito de qualificação profissional vem se alterando, com a presença cada vez maior de componentes associados às capacidades de coordenar informações, interagir com pessoas, interpretar, de maneira mais dinâmica, a nova realidade do ensino da engenharia, calcados em competências e habilidades.

Agopyan (2005) defende que, para ter uma boa formação, o engenheiro do futuro precisará, além de se reciclar e estar sempre atualizado para responder ao dinamismo do mercado, voltar a integrar-se à comunidade, comprometendo-se com o desenvolvimento sustentável por meio do auto-aprendizado, adaptação e sensibilidade para os problemas sociais, do meio ambiente e da qualidade de vida. “ $O$ Novo Engenheiro precisa voltar a entender sua Responsabilidade Social" (AGOPYAN, 2005).

Novos desafios foram impostos às instituições formadoras de profissionais da engenharia, pois a velocidade dessas mudanças tecnológicas tem exigido estruturas curriculares mais flexíveis, que permitam alterações no conteúdo sempre que necessário, para manter a competitividade do profissional formado.

O Ministério da Educação - MEC regulamenta o setor e fiscaliza as Instituições de Ensino Superior controlando as autorizações e reconhecimentos de cursos através do Instituto Nacional de Estudos e Pesquisas Educacionais - Anísio Teixeira - INEP através do Sistema Nacional de Avaliação da Educação Superior SINAES, o Conselho Federal de Engenharia CONFEA fiscaliza a atuação dos profissionais de engenharia e as exigências do mercado profissional indicam os rumos ao futuro engenheiro.

\section{Evolução dos cursos de engenharia}

Giardino (2008) publicou na revista ValorInveste de junho/2008 artigo intitulado "Erro de cálculo" apresentando estudo da Confederação Nacional da Indústria - CNI informando que há atualmente no Brasil 6 engenheiros para cada 1000 trabalhadores, sendo que a média mundial é de 25 para cada 1000. Cita também que - em pesquisa desenvolvida pelo professor e economista Marcos Formiga da Universidade de Brasília - UnB o déficit de alunos de engenharia formados por ano é de 30000 .

Estudos da Organização para Cooperação e Desenvolvimento Econômico - OCDE, realizados em diversos países, demonstraram que na China, no ano de 2006 cerca de 400000 novos engenheiros foram direcionados ao mercado de trabalho; na Índia, cerca de 300000 estudantes saíram da universidade com o diploma de engenharia; na Coréia, esse número é de 80000 e no Brasil esse número cai para 30000.

Todavia o ensino de engenharia no Brasil vem evoluindo com destaque para o curso de Engenharia de Produção que passou de 32 cursos em 2000 para 308 cursos em 2008 (863\%), seguido pela Engenharia Ambiental que de 22 passou para 129 (486\%) no mesmo período (tabela 1).

Dados levantados no Portal SiedSup do INEP em 2004 apresentavam cursos 
de engenharia no Brasil no total de 1321 e observando o mesmo Portal em 2008 pode-se ver que esse número cresceu para 1878 cursos $(42 \%)$.

Tabela 1 - Evolução da oferta de cursos

\begin{tabular}{|l|c|c|c|c|c|c|c|c|c|}
\hline Engenharias & $\mathbf{2 0 0 0}$ & $\mathbf{2 0 0 1}$ & $\mathbf{2 0 0 2}$ & $\mathbf{2 0 0 3}$ & $\mathbf{2 0 0 4}$ & $\mathbf{2 0 0 5}$ & $\mathbf{2 0 0 6}$ & $\mathbf{2 0 0 8}\left({ }^{*}\right)$ & Crescimento(*) \\
\hline Produção & 32 & 39 & 44 & 50 & 67 & 93 & 128 & 308 & $863 \%$ \\
\hline Ambiental & 22 & 31 & 32 & 42 & 52 & 64 & 84 & 129 & $486 \%$ \\
\hline Elétrica & 86 & 100 & 109 & 110 & 114 & 132 & 132 & 236 & $174 \%$ \\
\hline Civil & 121 & 126 & 126 & 127 & 132 & 137 & 148 & 221 & $83 \%$ \\
\hline Mecânica & 62 & 67 & 69 & 68 & 68 & 71 & 73 & 128 & $106 \%$ \\
\hline
\end{tabular}

(Fonte: Revista ValorInveste - Junho 2008)

(*) atualização em 2008.

Entretanto, o número de formandos (tabela 2) se mantém sem crescimento expressivo nas engenharias tradicionais (figura 1) com exceção para os cursos de Engenharia de Produção que passou de 362 em 2000 para 1578 em 2006

Tabela 2 - Número de formandos

\begin{tabular}{|l|c|c|c|c|c|c|c|}
\hline Engenharias & $\mathbf{2 0 0 0}$ & $\mathbf{2 0 0 1}$ & $\mathbf{2 0 0 2}$ & $\mathbf{2 0 0 3}$ & $\mathbf{2 0 0 4}$ & $\mathbf{2 0 0 5}$ & $\mathbf{2 0 0 6}$ \\
\hline Civil & 5.115 & 5.220 & 5.243 & 5.043 & 4.951 & 4.953 & 5.001 \\
\hline Elétrica & 2.601 & 2.889 & 3.330 & 3.421 & 3.489 & 3.820 & 4.262 \\
\hline Mecânica & 1.750 & 1.799 & 1.850 & 1.923 & 1.916 & 1.930 & 2.057 \\
\hline Produção & 362 & 344 & 569 & 657 & 845 & 1.049 & 1.578 \\
\hline
\end{tabular}

(Fonte: Revista ValorInveste - Junho 2008)

Form andos em Engenharia

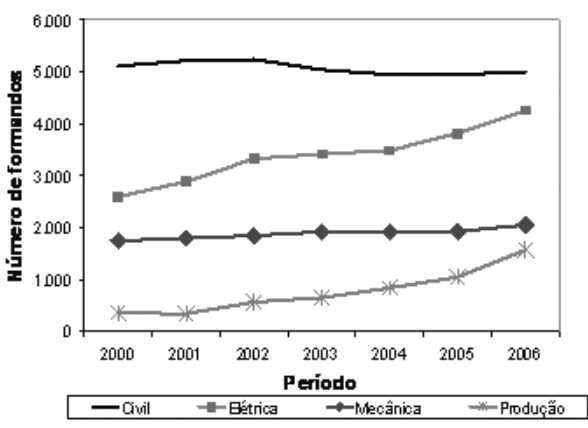

Figura 2 - Evolução no número de formandos em engenharia

\section{A Visão do Ministério da Educação- MEC}

O Ministério da Educação - MEC regulamenta o setor e fiscaliza as Instituições de Ensino Superior, controlando as autorizações e reconhecimentos de cursos através do Instituto Nacional de Estudos e Pesquisas Educacionais - Anísio Teixeira - INEP através do Sistema Nacional de Avaliação da Educação Superior - SINAES.

A doutrina orientadora da formação de um curso de engenharia utiliza como base a Lei de Diretrizes de Bases da Educação - LDB, Lei $\mathrm{n}^{\circ}$ 9.394, de 20 de dezembro de 1996, combinada com as Diretrizes Curriculares Nacionais - DCNs para os cursos de Engenharia, a Lei n ${ }^{\circ} 5.194$ de 24 de dezembro de 1966 que regula o exercício das profissões de Engenheiro, Arquiteto e Engenheiro-Agrônomo através do Conselho Federal de Engenharia - CONFEA e seus regionais, e ainda das exigências do mercado profissional.

O ensino no Brasil era organizado, há tempos atrás em níveis: primário, médio e superior. Com o advento da Lei n. ${ }^{\circ}$ 5.692/71 houve a reformulação do ensino no país na época, passando a dividir o ensino do país em $1^{\circ}$ e $2^{\circ}$ graus e superior. A nova reformulação pela Lei de Diretrizes e Bases da Educação Nacional, Lei ${ }^{\circ}$ 9.394, de 20 de dezembro de 1996, o ensino no Brasil passa adotar as categorias de fundamental, médio e superior, sendo que no nível superior, as Diretrizes Curriculares Nacionais foram abrindo espaço para estruturações curriculares diferenciadas e para inovações didático-pedagógicas, ampliando os conceitos dos currículos mínimos. Dentro dessa perspectiva, na estrutura curricular devem estar contemplados três tipos distintos de conteúdos:

- Básicos - voltados para a formação técnico-científica da área de conhecimento do curso;

- Profissionais - especificamente dirigidos

à efetiva preparação para o exercício profissional;

- Complementares - voltados para ampliar o leque de conhecimentos correlatos e permitir uma melhor preparação ética, humanística e técnica.

Para os cursos de engenharia, a Resolução CNE/CES n. ${ }^{\circ} 11$, de 11 de março de 2002, Diretrizes Curriculares Nacionais - DCNs para os cursos de Engenharia, determina que a formação do Engenheiro tem por objetivo dotar o profissional do conhecimento específico da profissão com competência e habilidade, tais como, aplicar conhecimentos matemáticos, científicos, tecnológicos e instrumentais, utilizandose da interdisciplinaridade do vocacional, desenvolvendo a ação instrumentada teórica da prática na Engenharia. Em seu artigo $3^{\circ}$, o Curso de Graduação em Engenharia orienta o perfil do formando egresso/profissional engenheiro, sua formação generalista, humanista, crítica e 
reflexiva, capacitado a absorver e desenvolver novas tecnologias, estimulando a sua atuação crítica e criativa na identificação e resolução de problemas. Que se considere os aspectos políticos, econômicos, sociais, ambientais e culturais, com visão ética e humanística, em atendimento às demandas da sociedade.

As DCNs também contemplam elementos de fundamentação essencial no campo do saber ou da profissão. Visa promover no estudante a capacidade de desenvolvimento intelectual e profissional, autônomo e permanente, e formas de aprendizagem que contribuam ao desenvolvimento de sua criatividade e análise crítica, tendo por objetivos desenvolver as seguintes competências e habilidades gerais:

I. aplicar conhecimentos matemáticos, científicos, tecnológicos e instrumentais à engenharia;

II. projetar e conduzir experimentos e interpretar resultados; conceber, projetar e analisar sistemas, produtos e processos;

III. planejar, supervisionar, elaborar e coordenar projetos e serviços de engenharia;

IV. identificar, formular e resolver problemas de engenharia; desenvolver e/ou utilizar novas ferramentas e técnicas;

V. supervisionar a operação e a manutenção de sistemas;

VI. avaliar criticamente a operação e a manutenção de sistemas;

VII. comunicar-se eficientemente nas formas escrita, oral e gráfica;

VIII. atuar em equipes multidisciplinares;

IX. compreender e aplicar a ética e responsabilidade profissionais;

X. avaliar o impacto das atividades da engenharia no contexto social e ambiental;

XI. avaliar a viabilidade econômica de projetos de engenharia;

XII. assumir a postura de permanente busca de atualização profissional.

Vale registrar também que os projetos pedagógicos de cursos de Engenharia devem estimular atividades complementares, tais como, trabalhos de conclusão de curso, trabalhos de iniciação científica, projetos multi e interdisciplinares, visitas técnicas, trabalhos em equipe, desenvolvimento de protótipos, monitorias e outras atividades empreendedoras que promovam e favoreçam a indissociabilidade entre ensino, pesquisa e extensão.

O egresso, além das competências na área de formação, deve também estar qualificado para o exercício da cidadania, sendo capaz de atuar criticamente na realidade em que se encontra inserido. Dessa forma, os conhecimentos construídos ao longo de sua formação profissional deverão capacitálos para agir diante desse cenário, além de possibilitar o gerenciamento da própria formação continuada e desenvolvimento profissional.

Aconstrução do perfil desejável para o profissional que está sendo lapidado, demanda o cuidado de preservar o reconhecimento regional do curso com o mercado existente.

\section{A Visão do Conselho Federal de Engenharia}

O Conselho Federal de Engenharia CONFEA atualizou as atribuições profissionais adequando as condições do Ministério da Educação através da Resolução do CONFEA $\mathrm{n}^{\mathrm{o}} 1.010$, de 22 de agosto de 2005, que dispõe sobre a regulamentação da atribuição de títulos profissionais, atividades, competências e caracterização do âmbito de atuação dos profissionais inseridos no Sistema Confea/ Crea, para efeito de fiscalização do exercício profissional, descrevendo o perfil do formando pela competência e sólida formação técnicocientífica, absorvendo e desenvolvendo novas tecnologias, estimulando a sua atuação crítica e criativa na identificação e solução de problemas, considerando seus aspectos políticos, econômicos, sociais, ambientais e culturais, com visão ética e humanística, em atendimento às demandas da sociedade, se servindo do aprendizado autônomo ou autoaprendizado.

Para efeito da regulamentação da atribuição de títulos, atividades e competências para os diplomados no âmbito das profissões inseridas no Sistema Confea/Crea, são considerados níveis de formação profissional superior:

- Graduação superior tecnológica;

- Graduação superior - bacharelado ou licenciatura;

-Pós-graduaçãonosensolato(especialização);

e 
- Pós-graduação no senso estrito (mestrado ou doutorado).

Quanto às funções e atribuições profissionais, os egressos dos cursos de engenharia estão sujeitos à:

- Supervisão, coordenação e orientação técnica;

- Estudo, planejamento, projeto e especificação;

- Estudo de viabilidade técnico-econômica;

- Assistência, assessoria e consultoria;

- Direção de obra e serviço técnico;

- Vistoria, perícia, avaliação, arbitramento, laudo e parecer técnico;

- Desempenho de cargo e função técnica;

- Ensino, pesquisa, análise, experimentação, ensaio e divulgação técnica; extensão;

- Elaboração de orçamento;

- Padronização, mensuração e controle de qualidade;

- Execução de obra e serviço técnico;

- Fiscalização de obra e serviço técnico;

- Produção técnica e especializada;

- Condução de trabalho técnico;

- Condução de equipe de instalação, montagem, operação, reparo ou manutenção;

- Execução de instalação, montagem e reparo;

- Operação e manutenção de equipamento e instalação;

• Execução de desenho técnico.

\section{A Estrutura Empresarial Brasileira e o Mercado de Trabalho dos Engenheiros}

Em recente pesquisa apresentada pelo Conselho Federal de Engenharia - CONFEA, Confederação Nacional da Indústria - CNI, Serviço Social da Indústria - SESI - Serviço Nacional de Aprendizagem industrial - SENAI e Instituto Euvaldo Lodi - IEL pode-se ter uma visão do mercado de trabalho de engenharia no Brasil e relacionar as implicações da estrutura do mercado empresarial brasileira com a estrutura do mercado de empresas que contrata engenheiros.
Tabela 3 - Estrutura do mercado empresarial brasileiro versus mercado de empresas que contrata engenheiros

\begin{tabular}{|c|c|c|c|c|c|}
\hline \begin{tabular}{|l} 
Descrição \\
\end{tabular} & Até 49 & $50-249$ & $250-499$ & 500 ou mais & TOTAL \\
\hline \begin{tabular}{|l} 
Total de empresas (Cadastro Central \\
de Empresas 2005 - IBGE)
\end{tabular} & 5.602 .381 & 50.736 & 7.526 & 7.360 & \begin{tabular}{|c|c|}
5.668 .003 \\
\end{tabular} \\
\hline$\%$ do total de empresas & $98,84 \%$ & $0,90 \%$ & $0,13 \%$ & $0,13 \%$ & $100,00 \%$ \\
\hline $\begin{array}{l}\text { Total de assalariados (Cadastro } \\
\text { Central de Empresas 2005 - IBGE) }\end{array}$ & 9.850 .592 & 4.987 .021 & 2.607 .345 & 14.779 .282 & 32.224 .240 \\
\hline \% do total de assalariados & $30,57 \%$ & $15,48 \%$ & $8,09 \%$ & $45,86 \%$ & $100,00 \%$ \\
\hline \begin{tabular}{|l} 
Salários e outras remuneraçōes em \\
RS 1.000,00 (Cadastro Central de \\
Empresas 2005-IBGE)
\end{tabular} & 76.988 .230 & 57.910 .677 & 34.766 .834 & 274.586 .870 & 444.252 .611 \\
\hline \% de remuneraçōes & $17,33 \%$ & $13,04 \%$ & $7,83 \%$ & $61,81 \%$ & $100,00 \%$ \\
\hline $\begin{array}{l}\text { Total de engenheiros (CAGED } \\
\text { 30/01/2007) } \\
\end{array}$ & 21.930 & 30.267 & 16.542 & 60.086 & 128.825 \\
\hline$\%$ do total de engenheiros contratados & $17,02 \%$ & $23,49 \%$ & $12,84 \%$ & $46,64 \%$ & $100,00 \%$ \\
\hline
\end{tabular}

Fonte: Mercado de trabalho para engenheiro e tecnólogo no Brasil - CNI-SESI-SENAI-IEL-CONFEA

Considerando os dados da tabela $3, \mathrm{o}$ mercado brasileiro é composto, principalmente por empresas com até 49 empregados, ou seja, $98,8 \%$ do total de empresas. Destas, 4.703 .404 $(82,98 \%)$ estão na faixa de 0 a 4 empregados. Já as empresas com mais de 500 empregados são apenas $0,13 \%$.

É nestas duas faixas que se concentra o maior número de assalariados do Brasil. Nas empresas de até 49 empregados são $30,57 \%$ dos assalariados e nas empresas com 500 empregados ou mais empregam outros $45,86 \%$.

Em termos de massa salarial, as empresas com 500 empregados ou mais são responsáveis por $61,81 \%$ do total da massa salarial e de remunerações, com a média salarial mais alta, próxima de 5 salários mínimos, contra os 2,2 salários mínimos das empresas com até 49 empregados.

Quando se trata da contratação de engenheiros, empresas com mais de 500 empregados continuam sendo as maiores empregadoras, com uma proporção de engenheiros contratados de $46,64 \%$, sendo praticamente igual à de assalariados com $45,86 \%$.

Outro dado relevante que a pesquisa mostra é a concentração de engenheiros contratados por ramo de atividade (tabela 4). Segundo o CAGED de 30/01/2007 tendo por Base a Relação Anual de Informações SociaisRAIS de 2004, 49,2\% do total de engenheiros empregados, isto é, quase metade está concentrada em cinco ramos de atividade. $\mathrm{O}$ ramo da construção lidera com o maior índice percentual de empregos aos engenheiros com 16.414 correspondendo a $14,8 \%$, sendo a grande concentração de empregados 7.655 está em empresas menores, de até 49 empregados. $\mathrm{O}$ ramo de serviços prestados principalmente às empresas vem em segundo com $12,9 \%$, compreendendo empresas de consultoria, projetos ou de terceirização de serviços. Outro ramo com forte índice de geração de empregos 
a engenheiros é a administração pública, defesa e seguridade social com 10,6\%, especificamente órgãos do governo.

Tabela 4 - CAGED de 30/01/2007 - Base RAIS de 2004

\begin{tabular}{|c|c|c|}
\hline $\begin{array}{c}\text { Divisão } \\
\text { CNAE }\end{array}$ & Ramos & Construção \\
\hline 45 & Serviços prestados principalmente às empresas & $12,9 \%$ \\
\hline 74 & $\begin{array}{c}\text { Administração pública, defesa e seguridade } \\
\text { social }\end{array}$ & $10,6 \%$ \\
\hline 75 & Eletricidade, gás e água quente & $6,0 \%$ \\
\hline 40 & $\begin{array}{c}\text { Fabricação e montagem de veículos } \\
\text { automotores, reboques e carrocerias }\end{array}$ & $5,0 \%$ \\
\hline 34 & Total de engenheiros & $\mathbf{4 9 , 2 \%}$ \\
\hline \multicolumn{2}{|c}{} \\
\hline
\end{tabular}

(Ramos que empregam 49,2\% do total de engenheiros)

Outros 26,5 \% dos engenheiros empregados estão em outros 9 ramos de atividade, com predomínio das empresas de 250 ou mais empregados (tabela 5).

Tabela 5 - CAGED de 30/01/2007 - Base RAIS de 2004

\begin{tabular}{|c|c|c|}
\hline $\begin{array}{c}\text { Divisão } \\
\text { CNAE }\end{array}$ & Ramos & $\%$ \\
\hline 64 & Correio e telecomunicações & $4,6 \%$ \\
\hline 29 & Fabricaç̃o de máquinas e equipamentos & $3,9 \%$ \\
\hline 41 & Captação, tratamento e distribuição de água & $3,0 \%$ \\
\hline 35 & Fabricação de outros equipamentos de transporte & $2,8 \%$ \\
\hline 24 & Fabricação de produtos químicos & $2,8 \%$ \\
\hline 23 & Fabricação de coque, refino de petróleo, elaboração de \\
combustiveis Nucleares & $2,5 \%$ \\
\hline 51 & Comércio por atacado e representantes comerciais e agentes \\
do comércio & $2,5 \%$ \\
\hline 27 & Metalurgia básica & $2,3 \%$ \\
\hline 31 & Fabricação de máquinas, aparelhos e materiais & $2,2 \%$ \\
\hline \multicolumn{2}{|c|}{ Total de engenheiros } & $\mathbf{2 6 , 5} \%$ \\
\hline
\end{tabular}

(Ramos que empregam 26,5\% do total de engenheiros)

Os $24,3 \%$ restantes (tabela 6) estão espalhados por 45 ramos de atividades diferentes, com forte predomínio das empresas de 250 a 499 empregados e, principalmente, empresas com 500 ou mais empregados. Os destaques preocupantes desse grupo ficam para os ramos da educação e da pesquisa e desenvolvimento, somente $0,9 \%$ dos engenheiros ativos que atuam na educação e $1,4 \%$ na pesquisa e desenvolvimento.

Tabela 6 - CAGED de 30/01/2007 - Base RAIS de 2004

\begin{tabular}{|c|c|c|}
\hline $\begin{array}{c}\text { Divisão } \\
\text { CNAE }\end{array}$ & Ramos & $\%$ \\
\hline 15 & Fabricação de produtos alimentícios e bebidas & $1,7 \%$ \\
\hline 60 & Transporte terrestre & $1,6 \%$ \\
\hline 52 & Comércio varejista e reparação de objetos pessoais e domésticos & $1,6 \%$ \\
\hline 28 & Fabricação de produtos de metal - exclusive máquinas e \\
equipamentos & $1,5 \%$ \\
\hline 11 & Extração de petróleo e serviços relacionados & $1,5 \%$ \\
\hline 32 & Fabricação de material eletrônico e de aparelhos e equipamentos \\
de comunicação & $1,4 \%$ \\
\hline 73 & Pesquisa e desenvolvimento & $1,4 \%$ \\
\hline 25 & Fabricação de artigos de borracha e plástico & $1,0 \%$ \\
\hline 65 & Intermediação financeira & $1,0 \%$ \\
\hline 13 & Extração de minerais metálicos & $1,0 \%$ \\
\hline 26 & Fabricação de produtos de minerais não metálicos & $0,9 \%$ \\
\hline 85 & Saúde e serviços sociais & $0,9 \%$ \\
\hline 80 & Educação & $0,9 \%$ \\
\hline 63 & Atividades anexas e auxiliares do transporte e agências de & $0,8 \%$ \\
& viagem & \\
\hline 33 & Fabricação de equipamentos de instrumentação para usos \\
& médico-hospitalares & $0,7 \%$ \\
\hline
\end{tabular}

\begin{tabular}{|c|c|c|}
\hline 21 & Fabricação de celulose, papel e produtos de papel & $0,7 \%$ \\
\hline 70 & Atividades imobiliárias & $0,6 \%$ \\
\hline 91 & Atividades associativas & $0,6 \%$ \\
\hline 72 & Atividades de informática e serviços relacionados & $0,6 \%$ \\
\hline 90 & Limpeza urbana e esgoto e atividades relacionadas & $0,5 \%$ \\
\hline 30 & $\begin{array}{l}\text { Fabricação de máquinas para escritório e equipamentos de } \\
\text { informática }\end{array}$ & $0,4 \%$ \\
\hline 14 & Extração de minerais não-metálicos & $0,3 \%$ \\
\hline 17 & Fabricação de produtos têxteis & $0,3 \%$ \\
\hline 36 & Fabricação de móveis e indústrias diversas & $0,3 \%$ \\
\hline 1 & Agricultura, pecuária e serviços relacionados & $0,3 \%$ \\
\hline 92 & Atividades recreativas, culturais e desportivas & $0,2 \%$ \\
\hline 50 & $\begin{array}{c}\text { Comércio e reparos de veículos autom. e motocicletas, comércio } \\
\text { a varejo de combustiveis }\end{array}$ & $0,2 \%$ \\
\hline 71 & $\begin{array}{l}\text { Aluguel de veículos, máquinas e equipamentos sem condutores } \\
\text { ou operadores }\end{array}$ & $0,2 \%$ \\
\hline 20 & Fabricação de produtos de madeira & $0,2 \%$ \\
\hline 62 & Transporte aéreo & $0,1 \%$ \\
\hline 67 & $\begin{array}{c}\text { Atividades auxiliares da intermediação financeira, seguros e } \\
\text { previdência complementar }\end{array}$ & $0,1 \%$ \\
\hline 61 & Transporte aquaviário & $0,1 \%$ \\
\hline 22 & Edição, impressão e reprodução de gravações & $0,1 \%$ \\
\hline 19 & $\begin{array}{l}\text { Preparação de couros e fabricação de artefatos de couro, artigos } \\
\text { de couro, etc. }\end{array}$ & $0,1 \%$ \\
\hline 55 & Alojamento e alimentação & $0,1 \%$ \\
\hline 65 & Seguros e previdência complementar & $0,1 \%$ \\
\hline 18 & Confecção de artigos do vestuário e acessórios & $0,1 \%$ \\
\hline 2 & Silvicultura, exploração florestal e serviços relacionados & $0,1 \%$ \\
\hline 10 & Extração de carvão mineral & $0,0 \%$ \\
\hline 93 & Serviços pessoais & $0,0 \%$ \\
\hline 37 & Reciclagem & $0,0 \%$ \\
\hline 16 & Fabricação de produtos do fumo & $0,0 \%$ \\
\hline 5 & Pesca, aqüicultura e serviços relacionados. & $0,0 \%$ \\
\hline 99 & Organismos internacionais e outras instituições extraterritoriais & $0,0 \%$ \\
\hline 95 & Serviços domésticos & $0,0 \%$ \\
\hline \multicolumn{2}{|r|}{ Total de engenheiros } & $24,3 \%$ \\
\hline
\end{tabular}

(Ramos que empregam 23,4\% do total de engenheiros)

\section{A Contratação e a Carreira dos Engenheiros pelas Empresas}

O caminho mais comum para entrada dos engenheiros na empresa é pela participação em programas de estágio durante o período de estudo ou após um período como trainee. A necessidade de estágios é apontada como crucial como forma de superar a barreira da falta da prática no ensino de engenharia e ao perfil do futuro profissional, melhorando inclusive o desempenho e a postura dos estudantes em sala de aula.

A empresa é vista como participante do processo de formação real do engenheiro para as necessidades do mercado. Quanto às correções ou ajustes que a educação de engenharia deveria sofrer, a questão da prática e do mercado de trabalho aparece sempre com destaque.

Se a entrada nas empresas depende de um período de estágio e treinamento, sua permanência dependerá cada vez mais de atualização e adaptação a novas técnicas e tecnologias. No panorama atual, um engenheiro pode esperar mudar de emprego 4 vezes entre a formatura e a aposentadoria, já que seu tempo de permanência médio na empresa é de 8,2 anos (figura 2). 


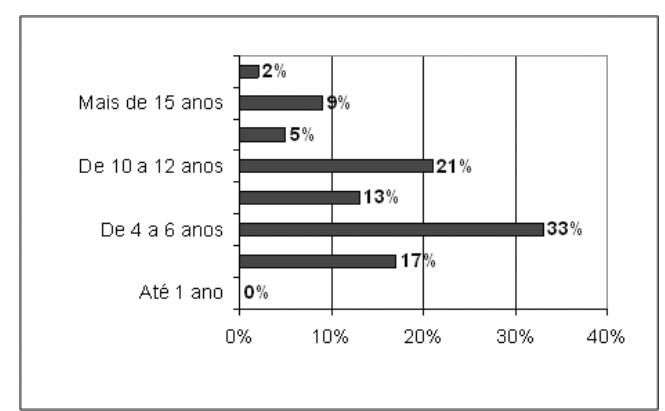

(Fonte: Revista ValorInveste - Junho 2008)

Figura 2 - Permanência do engenheiro na empresa

Quanto aos salários, pode-se observar a presença da lei de mercado de oferta e procura com a evolução crescente tanto para a categoria de engenheiro sênior quanto para engenheiro júnior no período de 2005 a 2008 (tabela 7)

Tabela 7 - Salários anuais em R - remuneração fixa + bônus pagos (média)

\begin{tabular}{|l|c|c|c|}
\hline & $\mathbf{2 0 0 5}$ & $\mathbf{2 0 0 8}$ & Variações \\
\hline Engenheiro civil sênior & $53.000,00$ & $98.000,00$ & $85 \%$ \\
\hline Engenheiro mecânico sênior & $62.000,00$ & $95.000,00$ & $53 \%$ \\
\hline Engenheiro elétrico sênior & $67.000,00$ & $93.000,00$ & $39 \%$ \\
\hline Engenheiro de projetos sênior & $55.000,00$ & $90.000,00$ & $64 \%$ \\
\hline Engenheiro de produção sênior & $60.000,00$ & $90.000,00$ & $50 \%$ \\
\hline Engenheiro civil júnior & $37.000,00$ & $68.500,00$ & $85 \%$ \\
\hline Engenheiro de projetos júnior & $40.000,00$ & $66.500,00$ & $66 \%$ \\
\hline Engenheiro mecânico júnior & $44.000,00$ & $66.500,00$ & $51 \%$ \\
\hline Engenheiro de produção júnior & $41.000,00$ & $65.000,00$ & $59 \%$ \\
\hline Engenheiro elétrico júnior & $42.000,00$ & $65.000,00$ & $55 \%$ \\
\hline
\end{tabular}

(Fonte: Revista ValorInveste - Junho 2008)

\section{A crescente oferta de vagas oferecidas} pelas empresas para os engenheiros cresceu $38,88 \%$ no período de 2006 e 2007 frente a demais profissões (tabela 8).

Observa-se ainda a evolução e correção de salários dos Engenheiros Civis, passando a ser o maior valor absoluto em relação às demais modalidades de engenharia em valor anual, tendo a maior evolução salarial com valor relativo de $85 \%$.

Tabela 8 - Total de vagas oferecidas pelas empresas

\begin{tabular}{|l|c|c|c|}
\hline & $\mathbf{2 0 0 6}$ & $\mathbf{2 0 0 7}$ & Variações \\
\hline Engenheiro & 7703 & 10698 & $38,88 \%$ \\
\hline Administração de Empresas & 6194 & 6487 & $4,73 \%$ \\
\hline Tecnologia da Informação & 4584 & 3825 & $-16,56 \%$ \\
\hline Ciências Contábeis & 3269 & 3439 & $5,20 \%$ \\
\hline Economia & 2254 & 2343 & $3,95 \%$ \\
\hline Publicidade, propaganda e marketing & 968 & 999 & $3,20 \%$ \\
\hline Psicologia & 857 & 822 & $-4,08 \%$ \\
\hline Direito & 538 & 614 & $14,13 \%$ \\
\hline Comunicação & 188 & 341 & $81,38 \%$ \\
\hline Comércio exterior & 368 & 398 & $8,15 \%$ \\
\hline
\end{tabular}

(Fonte: Manager - Revista ValorInveste - Junho 2008)

\section{Conclusão}

A falta de mão-de-obra especializada em diversos setores da economia atinge seriamente a área tecnológica, especialmente a todos os ramos da engenharia. A abertura ao mercado internacional, a entrada de multinacionais, a privatização da telefonia, a expansão do setor de petróleo e gás e a própria apresentação do PAC (Programa de Aceleração do Crescimento) expõem a carência de engenheiros brasileiros habilitados.

A presença cada vez maior de engenheiros estrangeiros no mercado de trabalho nacional cresce a cada ano, sendo somente considerada a entrada no país de 600 chineses a serem trazidos pela CSA (Companhia Siderúrgica do Atlântico) que está sendo construída em Santa Cruz, no Rio de Janeiro, para produzir coque, uma das matérias-primas do aço.

Os chineses são uma novidade entre os estrangeiros que vêm trabalhar no Brasil. O país é normalmente procurado por espanhóis e portugueses. Os mercados-de-trabalho de São Paulo, Minas Gerais e Rio de Janeiro ressentem da escassez de profissionais devidamente habilitados, e a conseqüência disso é a oferta de salários crescentes. O salário inicial para engenheiros recém formados saltou de $\mathrm{R} \$ 1,5$ mil para $\mathrm{R} \$ 4$ mil nos últimos três anos.

O Ministério da Educação - MEC e o Conselho Federal de Engenharia - CONFEA assinaram convênio permitindo ao CONFEA participar da avaliação dos cursos de engenharia já existentes e a criação de novos, demonstrando a preocupação com a qualidade na formação profissional.

O estudo realizado pelo CONFEA, CNI, SESI, SENAI e o IEL ensina que para se entender o mercado de trabalho de engenharia no Brasil é preciso analisar a estrutura do mercado empresarial e a estrutura do mercado de empresas que contrata engenheiros, sendo que no Brasil, somam 5.603.311 as empresas que contratam até 49 empregados. Destas, 4.703.404 contratam de zero a quatro empregados. As empresas com 500 ou mais empregados são apenas 7.360. As empresas com até 49 empregados concentram 30,57\% dos assalariados. As com 500 empregados ou mais, empregam $45,86 \%$ e são elas, de médio porte, entre 50 a 500 empregados, que relativamente empregam mais engenheiros, $56 \%$ mais que as grandes empresas e $178 \%$ mais do que as com até 49 empregados.

As empresas com até 49 empregados 
somam 5.602.381, e contratam perto de 22 mil engenheiros. As empresas com até 249 empregados têm 30.267 engenheiros em seus quadros. As com até 499, respondem por quase $17 \mathrm{mil}$ contratações; com 500 ou mais funcionários, contratam cerca de $61 \mathrm{mil}$ engenheiros.

Do total de engenheiros empregados, praticamente a metade se concentra em cinco ramos de atividade, sendo que dois deles estão fora das diretamente relacionadas à produção. Um é formado por empresas que prestam consultoria (16.600), projetos ou de terceirização de serviços. O outro é a administração pública (defesa e seguridade social). A construção civil - com empresas de até 49 empregados - é o ramo da engenharia que mais contrata, cerca de 19 mil, ou 14,8\% do total de $49,2 \%$ engenheiros contratados. A consultoria fica com $12,9 \%$ das contratações seguida da administração pública, defesa e seguridade social, 10,06\%; eletricidade, gás e água quente, $6 \%$ e fabricação e montagem de veículos automotores, reboques e carrocerias, $5 \%$. Esses cinco ramos são seguidos por: telecomunicações $4,6 \%$; fabricação de máquinas e equipamentos $3,9 \%$; captação, tratamento e distribuição de água 3\%; fabricação de produtos químicos 2,8\%, fabricação de coque, refino de petróleo, elaboração de combustíveis nucleares 2,5\%.

O mercado de trabalho registra poucas empresas que empregam grande quantidade de engenheiros. As que têm em seus quadros até cinco engenheiros representam mais de $60 \%$ do mercado. As grandes empregadoras, com mais de 100 engenheiros, são apenas 2,8\% do total. $\mathrm{Na}$ grande maioria das empresas, aparecem com mais destaque os engenheiros civis, seguidos dos eletricistas e eletrônicos e dos mecânicos.

Quanto a estudantes de engenharia, $64 \%$ das empresas contratam estagiários e $36 \%$ contratam trainees, $41 \%$ dão treinamento e apenas 21\% (79\% delas não usam esse recurso) das empresas buscam programas para atrair engenheiros em final de formação ou recém-formados.

O tempo médio de permanência na empresa é de 8,2 anos e $82 \%$ das empresas procuram evitar que os engenheiros peçam demissão, oferecendo planos de carreira e salários específicos, baseados em avaliação de desempenho, distribuição de lucros, aumento salarial por tempo na empresa e bônus, associado ao desempenho da empresa como um todo.

Finalmente, como os cursos de engenharia no Brasil poderão acompanhar o quadro acima se a contratação de engenheiros para atividades de pesquisa e desenvolvimento é de $1,4 \%$ e para atividades de educação é de apenas $0,9 \%$ dos profissionais devidamente habilitados (tabela 6)?

\section{Referências}

AGOPYAN, Vahan. A engenharia do século XXI. Guia do estudante - profissões engenharia. São Paulo, SP, ano1, n. 1, p. 0911, 2005.

BRASIL. Lei 9.394, de 20 de dezembro de 1996. Estabelece as Diretrizes e Bases da Educação Nacional. Educação superior: Legislação Básica. Disponível em http:// www.mec.gov.br/legis/default.shtm\#superior

Resolução CNE/CES n. ${ }^{\circ}$ 11, de 11 de março de 2002. Institui Diretrizes Curriculares Nacionais do Curso de Graduação em Engenharia. Disponível em $<$ http://www.mec.gov.br/cne/resolucao. shtm\#3>

CONSELHO FEDERAL DE ENGENHARIA, ARQUITETURA E AGRONOMIA CONFEA. Resolução $\mathbf{n}^{\mathbf{0}} \mathbf{1 . 0 1 0}$, de 22 de agosto de 2005 - Dispõe sobre a regulamentação da atribuição de títulos profissionais, atividades, competências e caracterização do âmbito de atuação dos profissionais inseridos no Sistema Confea/ Crea, para efeito de fiscalização do exercício profissional. Disponível em $<$ http://www. confea.org.br/publique/media/res1010.pdf $>$

Resolução no 218, de 29 de junho de 1973 - Discrimina atividades das diferentes modalidades profissionais da Engenharia, Arquitetura e Agronomia. Disponível em <http://creaapp.crea-rj.org. br/pls/ portal / docs / page / portal_crea_rj / arquivos / pdf / resolucao / resolucao $\% 20$ n218.pdf $>$

Mercado de trabalho para o 
engenheiro e tecnólogo no Brasil. Disponível em <http://www.confea.org.br/publique/ media/RelatoriodaPesquisaRevisado2008. pdf $>$

GIARDINO, Andréa. Erro de cálculo. Valor Investe - carreiras. São Paulo, SP, ano 6, n. 18, p. 28-32, jun. 2008.

Endereço para Correspondência:

Prof. Sergio Luiz Taranto de Reis

Cursos de Engenharias

sergio.reis@foa.org.br

Centro Universitário de Volta Redonda

Campus Três Poços

Av. Paulo Erlei Alves Abrantes, $n^{\circ}$ 1325,

Três Poços - Volta Redonda / RJ

CEP: $27240-560$

Informações bibliográficas:

Conforme a NBR 6023:2002 da Associação Brasileira de Normas Técnicas (ABNT), este texto científico publicado em periódico eletrônico deve ser citado da seguinte forma:

REIS, S. L. T.. Os Cursos de Engenharia e seus Setores Regulador, Fiscalizador e de Livre Iniciativa de Mercado, Volta Redonda, ano III, n. 7, agosto. 2008. Disponível em: <http://www.unifoa. edu.br/pesquisa/caderno/edição/07/11.pdf> 